\title{
Alternative Curing Methods
}

\author{
Lisa Siekmann ${ }^{1} \cdot$ Madeleine Plötz $^{1} \cdot$ Carsten Krischek $^{1}$
}

Accepted: 18 February 2021 / Published online: 13 March 2021

(C) The Author(s) 2021

\begin{abstract}
Purpose of Review Curing — the treatment of meat products with nitrite and nitrate—is controversially discussed by consumers, as increased consumption of cured foods might negatively influence human health.

Recent Findings However, omitting of curing chemicals might reduce microbiological safety, thereby increasing the risk to consumer health. Also, besides the addition of nitrate/nitrite, meat products are additionally preserved within the hurdle principle by other methods such as chilling, ripening, or heating.

Summary The present article focuses on the addition of plants/plant extracts or plasma-treated water as nitrate sources and the direct treatment of meat products with plasma for nitrate generation. With regard to color and microbial safety of cured meat products, which are relevant to the consumers, promising results were also obtained with the alternative curing methods. Nonetheless, it is doubtful to what extent these methods are viable alternatives, as the curing chemicals themselves and not their origin are problematic for consumer health.
\end{abstract}

Keywords Plant-derived nitrites $\cdot$ Nitrogen species in plasma $\cdot$ Nitrite-free curing $\cdot$ Meat products $\cdot$ Bacterial inactivation $\cdot$ Sensory characteristics

\section{Introduction}

For many centuries, salt has been used to preserve meat. In the meantime, potassium nitrate, contained in salt, has been proven to play an important role in the preservative effect of curing [1-3]. Potassium and sodium nitrite $\left(\mathrm{E} 249-\mathrm{KNO}_{2}, \mathrm{E} 250\right.$ $\left.\mathrm{NaNO}_{2}\right)$ and potassium and sodium nitrate $\left(\mathrm{E} 251-\mathrm{KNO}_{3}\right.$, $\mathrm{E} 252-\mathrm{NaNO}_{3}$ ) are approved food additives in the European Union (EU), and their use in meat products is generally limited to $150 \mathrm{mg} / \mathrm{kg}$ [4]. Whereas nitrite $\left(\mathrm{NO}_{2}{ }^{-}\right)$is a frequently

This article is part of the Topical Collection on Bacteriology

Lisa Siekmann

lisa.siekmann@tiho-hannover.de

Madeleine Plötz

madeleine.ploetz@tiho-hannover.de

Carsten Krischek

carsten.krischek@tiho-hannover.de

1 Institute for Food Quality and Food Safety, Foundation University of Veterinary Medicine Hannover, Bischofsholer Damm 15, D-30173 Hannover, Germany used food additive, nitrate $\left(\mathrm{NO}_{3}{ }^{-}\right)$is mainly applied for longterm reservoirs in slow-cured products [5].

In general, using nitrites as well as nitrates as food additives offers many advantages. After adding nitrite to the mildly acidic meat matrix ( $\mathrm{pH} 5.5$ ), it is reduced to nitric oxide (NO) [6]. NO is gaseous and interacts with the heme subunit of myoglobin [2] forming the "nitrosomyoglobin" complex responsible for the typical reddish-pink color of cured meat [2,6-8]. To induce this effect, more than $20 \mathrm{ppm}$ are needed. As the residual nitrite in meat functions as a reservoir, more than 50 $60 \mathrm{ppm}$ should be added to the meat to ensure a stable color during prolonged storage [3]. At the end of the curing process, $5-15 \%$ of nitrite is bound to the heme proteins myoglobin and hemoglobin, 20-30\% to non-heme proteins, and $1-5 \%$ to lipids, whereas $1-5 \%$ escape from the product in a gaseous form [2]. Additionally, nitrite is oxidized to nitrate by microorganisms or remains as a residual nitrate in raw meat $[1,6]$.

Applying nitrite increases the (microbial) safety of the meat products, as the salt specifically inhibits the growth of Clostridium $(\mathrm{Cl}$.) botulinum $[9,10]$ and $\mathrm{Cl}$. perfringens $[11$, 12]. This inhibiting effect is more effective at low $\mathrm{pH}$ values $[9,13]$, as beside the general effect of the $\mathrm{pH}$ value $\mathrm{HNO}_{2}$ and 


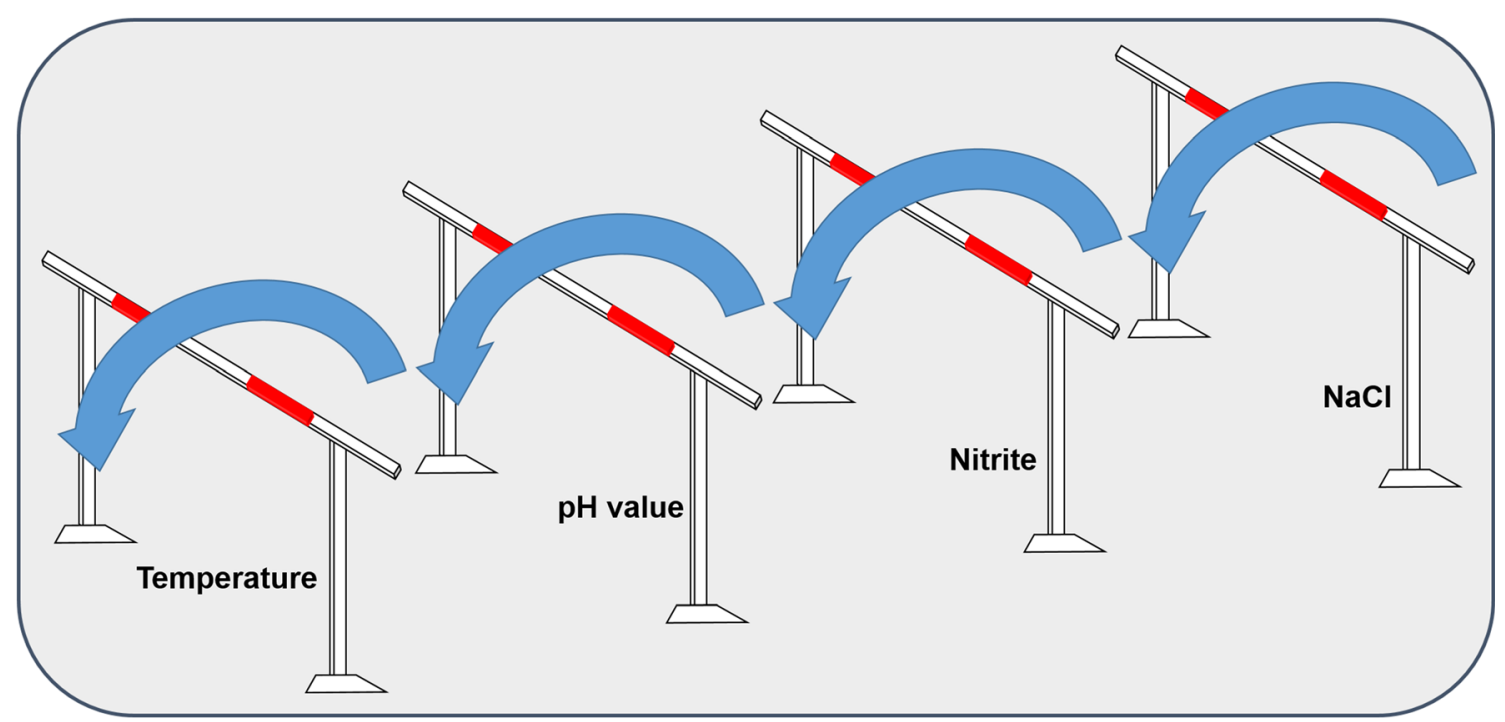

Fig. 1 Demonstration of the hurdle principle. The combination of different parameters, e.g., salt $(\mathrm{NaCl})$ content, nitrite content, $\mathrm{pH}$ value, and temperature, is used to ensure product quality and prolong shelf-life

NO are formed [14]. As a rule, the multiple hurdle approach is recommended for ensuring food quality (Fig. 1). In this approach, different preservation methods such as salting, drying, or heating might be used in combination to improve the overall food safety, especially with regard to certain risks, and additionally reduce possible negative effects of a single method on the food quality. For example, sterilization might be a good method to reduce the risk of bacterial contamination, but the method might also have a negative impact on the sensory results or the food composition (i.e., thermo-sensitive substances like vitamins).

Furthermore, nitrite can diminish lipid oxidation $[2,6]$, as the NO catches free iron preventing the initiation of oxidation steps $[7,10]$. Nitrite is also involved in the development of the typical taste and aroma of cured meat products, partly due to its inhibiting effect on lipid oxidation and development of rancidity. Beyond that, it contributes to the characteristic texture of cured meat $[2,15]$. Gassera et al. [16] summarize the antioxidative and antibacterial effects of $\mathrm{NO}_{3}{ }^{-}$and $\mathrm{NO}_{2}{ }^{-}$along with the influence of color and taste in meat products. In addition, the authors briefly outline toxicokinetic data of nitrite and nitrate, as besides the advantages of nitrate and nitrite, there are some concerns regarding the use of these substrates as food additives. In 2017, the European Food Safety Authority (EFSA) re-evaluated and confirmed the acceptable daily intake (ADI) concentrations for nitrate and nitrite and ADI levels of $3.7 \mathrm{mg} / \mathrm{kg}$ body weight for nitrate and 0.06 and $0.07 \mathrm{mg} / \mathrm{kg}$ body weight for nitrite as recommended by the EU Scientific Committee for Food (SCF) and the Joint FAO/WHO Expert Committee on Food Additives (JECFA) [17, 18].

Nitrite can react with amines present in raw meat and the human gastrointestinal tract resulting in the formation of nitrosamines $[2,17,18]$. The latter is influenced by the $\mathrm{pH}$ value, the presence of secondary amines, and the temperature. Temperatures around $130^{\circ} \mathrm{C}$ (e.g., during heating processes) allow for nitrosamine formation $[6,14]$. There are indications suggesting that consumption of cured meat products over longer periods leads to an increased risk of cancer development $[14,17,18]$. In this context, higher incidence rates of colorectal and gastric cancer were related to increased dietary $\mathrm{NO}_{3}{ }^{-} /$ $\mathrm{NO}_{2}{ }^{-}$intake via meat or milk products [18].

Besides the nitrosamine formation, nitrite and nitrate might oxidize heme $\mathrm{Fe}^{2+}$ within the hemoglobin to $\mathrm{Fe}^{3+}$ forming methemoglobin, which no longer binds oxygen. Therefore, methemoglobinemia might be life-threatening due to the development of hypoxia. An excessive intake of $\mathrm{NO}_{3}{ }^{-} / \mathrm{NO}_{2}{ }^{-}$is especially dangerous for children, as they exhibited lower methemoglobin reductase activities in comparison to adults [18]. The consequence might be the "baby blue syndrome", especially in children under the age of 6 months [19].

Several aspects influence residual nitrite levels in cured meat products [20]. Basically, $50-70 \%$ of the ingoing $\mathrm{NO}_{2}{ }^{-}$is retrievable in meat products directly after processing. Food additives such as ascorbate that support the formation of NO reduce these residual levels [5]. Complementary, thermal processing can reduce the nitrite content by up to $80 \%$ [2], whereas a 4week storage period can do so by up to $45 \%$ [21]. Different publications indicate that the concentrations of $\mathrm{NO}_{3}{ }^{-} / \mathrm{NO}_{2}{ }^{-}$, originating from plants and/or produced by cold plasma, decrease faster during the processing and storage of meat products [21-27]. To confirm this, further research is required.

In a large-scale study with more than 800 participants, Rava et al. [28] could not find any relation between the consumption of cured meat products and $\mathrm{NO}_{2}{ }^{-} / \mathrm{NO}_{3}{ }^{-}$levels in blood plasma. In contrast to this, consumption of leafy vegetables led to increased levels of nitrite in blood plasma. In 
recent years, the fundamental role of $\mathrm{NO}_{2}{ }^{-} / \mathrm{NO}$ in the body and several positive health benefits and novel therapies have been associated with sodium nitrite, especially $\mathrm{NO}$ [7, 29]. For an overview of the metabolic pathways of $\mathrm{NO}_{2}{ }^{-}$and $\mathrm{NO}_{3}{ }^{-}$, associated benefits and risks, the results of previous animal studies, and the link to the development of cancer, the review article by Habermeyer et al. [30] should be referred to. In several review articles, the effects of dietary nitrate and nitrite as well as efforts to reduce $\mathrm{NO}_{2}{ }^{-} / \mathrm{NO}_{3}{ }^{-}$levels are summarized $[8,31,32]$.

Although synthetically produced $\mathrm{NO}_{2}{ }^{-} / \mathrm{NO}_{3}{ }^{-}$molecules and those originating from vegetables are essentially chemically identical [33], doubts about using synthetical $\mathrm{NO}_{2}{ }^{-} / \mathrm{NO}_{3}{ }^{-}$ exist. This leads to a growing demand in meat production for alternative curing methods based on vegetable (extracts) with high nitrate contents [5].

In this article, we summarize the state of the art in research of alternatives to $\mathrm{NO}_{3}{ }^{-}$and $\mathrm{NO}_{2}{ }^{-}$as food additives in meat products. Therefore, the most recent findings in this field will be presented in three parts: firstly, curing methods with plantbased nitrite and nitrate, secondly, curing with nitrite and nitrate generated by cold atmospheric plasma, and lastly, curing without applying any of these food additives.

\section{Natural Curing-a Healthier Alternative?}

To satisfy the growing interest of consumers concerning naturally cured meat products [5], curing is performed with ingredients such as parsley, celery, cabbage, spinach, beetroot, lettuce, or radish, each as an extract or powder [2, 11, 24-27, 34-39]. Due to the wide field of plant-based nitrite sources, this review focuses on vegetables as the source of nitrate and nitrite.

The term "alternative curing" refers to the process that specific microorganisms reduce nitrate within these plant sources to nitrite. Nitrate-reducing bacteria which are used are coagulase negative cocci such as Staphylococcus (S.) carnosus or S. xylosus [25, 38, 40-42]. The extent of nitrate reduction is achieved by certain temperature/time combinations $[24,34$, 40]). Generally, converted nitrite content increases during the incubation of the bacteria up to $24 \mathrm{~h}$, followed by a decrease during longer incubation periods, especially in combination with high salt concentrations [34.•]. Three different methods are used to reduce nitrate to nitrite within the plant source: the culture system, the prebrine system, and the preconverted system. In the culture system, nitrite is produced by the bacteria within the product after mixing the plant (extract) and the other ingredients. In the prebrine system, the plant source is mixed with the bacteria and incubated under specific conditions. Thereafter, this mixture is added to the meat product. In contrast, in a preconverted system, the incubation of bacteria and plant (extract) is performed, as previously described, but the resulting solution is adjusted to a certain nitrite concentration and sold to meat product companies (Fig. 2). This method is most often used, as the nitrite content is adjusted before mixing with the other ingredients of the meat product [3].

In 2016, Pietrasik et al. [35] evaluated the effects of celery powder (CE) on the quality of cooked ham. Celery might be a good ingredient for meat products, as it has a mild flavor profile and a very limited impact on color due to its low pigment content [5]. CE hams had higher $\mathrm{pH}$ values mainly due to the high $\mathrm{pH}$ values of the celery powder. Besides similar color and thiobarbituric acid reactive substances (TBARS) results, the waterholding capacity and residual nitrite content of the CE products were higher in comparison to the hams treated with sodium nitrite (SN). CE-hams showed a more pronounced springiness, were less chewy and cohesive, and had a softer texture. At nitrite concentrations comparable to conventional curing, celery reduces the growth of $\mathrm{Cl}$. perfringens, in particular, in combination with ascorbates [33].

After a 30-day ripening period, the production of salamis with rosemary extract and celery extracts results in similar sensory qualities compared to salami produced with comparable SN concentrations [36 ${ }^{\bullet}$. However, shorter ripening periods reduce the ratings for odor and flavor due to the smell and taste of the ingredients of the extracts used [36॰].

Adding parsley extract powder (PE) to mortadella-type sausages resulted in lower $\mathrm{pH}$ values and residual nitrite contents and higher $\mathrm{b}^{*}$ values probably due to PE pigments [24••]. By increasing the PE content up to $120 \mathrm{ppm}$ nitrate, color development and stability were improved, and the growth of Listeria (L.) monocytogenes inhibited [24••].

The use of fermented beetroot (BR) as nitrate source for Frankfurter sausages leads to lower $\mathrm{pH}$ as well as lightness $\left(L^{*}\right)$ and yellowness $\left(b^{*}\right)$ values [37॰]. After refrigeration for 4 weeks of refrigerated storage, TBARS levels and total viable counts of the BR sausages were lower. However, overall acceptability of the sausages decreased with higher BR levels [37॰].

In another study, Hwang et al. [25] analyzed raw and cooked pork sausages cured with preconverted nitrites from celery, beetroot, spinach (SP), and lettuce (LC). Sausages produced using alternative curing methods showed lower $\mathrm{pH}$, redness $\left(\mathrm{a}^{*}\right)$, and residual nitrite levels but higher $\mathrm{b}^{*}$ values. Residual nitrite levels were highest in the SN sausages, followed by the products produced with $\mathrm{SP}, \mathrm{LC}$, and $\mathrm{CE}$, respectively. Interestingly, cooked SP samples achieved the highest $\mathrm{a}^{*}$ values, whereas TBARS concentrations were lowest for the SP and LC sausages [25].

If sliced pork loin is mixed with fermented spinach extracts and incubated with S. carnosus for 3 to $48 \mathrm{~h}$ [38•], with increasing incubation duration, a higher amount of nitrate is reduced to nitrite. These products had higher residual nitrite concentrations, $\mathrm{L}^{*} \mathrm{a} * \mathrm{~b} *$ results $\mathrm{pH}$ values (raw and cooked), and TBARS concentrations compared to the products cured with SN. A $24 \mathrm{~h}$ 


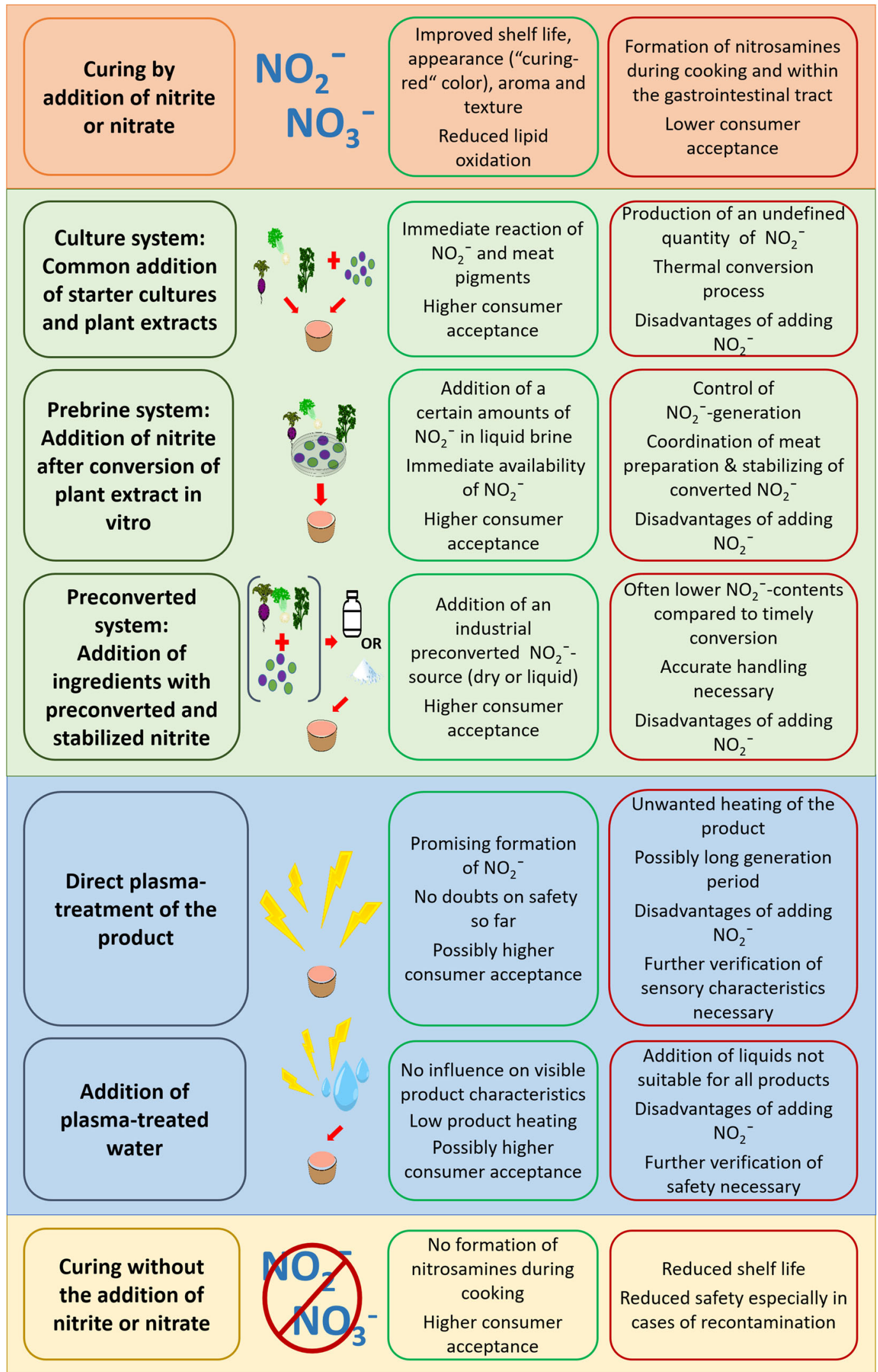

Fig. 2 Comparison of different curing methods: Curing with the addition of nitrite (red box), with plant-based nitrite (green box), with plasmabased nitrite (blue box), and without the addition of nitrite or nitrate (yellow box). Advantages of each method are highlighted with a green border, while disadvantages are highlighted with a dark red border 
incubation period gave the best results, as longer incubation leads to impaired sensory quality [38•].

If ground pork is mixed with $30 \mathrm{ppm}$ nitrate from spinach, radish (RD), and Chinese cabbage powder (CCP), all these products had higher $\mathrm{pH}$ and TBARS levels and lower residual nitrite contents. In contrast, adding RD resulted in similar $\mathrm{a}^{*}$ and $b^{*}$ values compared to SN samples, and lower $\mathrm{L}^{*}$ and $\mathrm{a}^{*}$ and higher $\mathrm{b}^{*}$ values were found, if CCP and SP were used. The authors conclude that $\mathrm{RD}$ is the most promising substitute due to its similarity in color, pigment, and curing efficiency when compared to SN-treated products [27•].

If cooked sausages were treated with cabbage, white radish, young radish (YRD), spinach, and lettuce and stored for 28 days, no effect on the TBARS results compared to the SN sausages

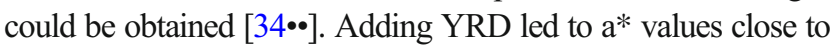
the results of the SN-control sausages, Therefore, YRD seems to be superior compared to the other plants, especially as a preservative against $L$. monocytogenes [34••].

In a recent study, Choi et al. [26] used white kimchi powder (a traditional fermented Korean food made from cabbage and radish, KP) as well as celery powder, both in combination with acerola juice powder, to produce cooked ground pork products. Besides lower $\mathrm{pH}$ values $(\mathrm{CE}<\mathrm{KP}<\mathrm{SN})$, higher $\mathrm{b}^{*}$ values were found for all powders. The residual nitrite levels increase with higher ingoing content of plant extracts but were still lower than those within the SN samples. It is interesting to note that higher amounts of acerola juice decrease the residual nitrite concentrations due to the accelerated conversion of nitrite to nitric oxide [26].

Although the different studies indicate that $\mathrm{NO}_{3}{ }^{-}$and/or $\mathrm{NO}_{2}{ }^{-}$from plant sources might be an alternative to using purified sodium/potassium nitrite/nitrate in meat products, there are several (regulatory) concerns whether these ingredients are viable alternatives. These doubts cannot be dispelled by the regulation that products with plant (extracts) labeled with "naturally cured," "alternatively cured," or "organic" may only be sold without the addition of purified nitrate and/or nitrite. However, in the USA, these substances were evaluated by the Food Safety and Inspection Services (FIS) and are permitted for the production of organic food. In member states of the EU and the European Free Trade Association (EFTA) states, the use of plant products as sources of nitrate has been prohibited until now, as these are classified as food additives when used to influence the color or the growth of microorganisms in accordance with Regulation (EC) No. 1333/2008 [4]. None of the plants or products thereof have been approved as food additives.

\section{Curing with Nitrate/Nitrite from Atmospheric Plasma}

The use of (cold) atmospheric plasma (plasma) as a recognized method for food decontamination purposes, packaging materials, or medical products has been intensively investigated during the last years [43, 44]. Plasma is generated by electric tension and represents the so-called fourth state of matter [44]. It consists of several reactive oxygen and nitrogen species like nitric oxide, nitrogen dioxide $\left(\mathrm{NO}_{2}\right)$, hydroxyl radicals $\left(\mathrm{OH}^{-}\right)$, superoxide $\left(\mathrm{O}_{2}^{-}\right)$, ozone $\left(\mathrm{O}_{3}\right)$, peroxynitrite $\left(\mathrm{ONOO}^{-}\right)$, as well as hydrogen peroxide $\left(\mathrm{H}_{2} \mathrm{O}_{2}\right)[43,45,46]$.

As nitrite and nitrate are also formed during plasma generation, some studies investigated whether plasma or plasmatreated water (PTW) might be an interesting alternative for the curing of meat products (Fig. 2) [21, 22, 47-56].

For example, Jung et al. [50] observed significantly lower redness values in PTW meat batters due to lower nitrite concentrations in PTW batters (46 ppm) compared to sodium nitrite-treated products $(70 \mathrm{ppm})$. Nevertheless, curing with PTW can result in the development of typical curing color [50]. Jung et al. [21] also compared the quality of conventional emulsion-type sausages, cured with $\mathrm{SN}$ as well as with PTW. As the amount of added nitrite in meat products in South Korea is restricted to $70 \mathrm{mg} / \mathrm{kg}$, similar nitrite concentrations $(70 \mathrm{mg} / \mathrm{kg}$ ) were achieved for both groups. The PTW sausages showed higher values of lightness as well as lower values of yellowness and redness than SN products. It is interesting to note that the residual nitrite levels in PTW products were lower than in the SN products. The authors suggested that this effect is due to a more rapid reduction in $\mathrm{NO}_{2}{ }^{-}$to $\mathrm{NO}$ or a shorter reaction time with the reducing agent "ascorbic acid" in PTW products. As residual nitrite levels usually declined during storage time, this might be risky in terms of microbial stability. However, despite the differing residual nitrite levels, the total aerobic bacteria counts of $\mathrm{SN}$ - and PTW-cured sausages were comparable, like the sensory and TBARS results (indicator of lipid oxidation). Therefore, Jung et al. claimed PTW to be a potential nitrite source for curing of meat products [21].

Kim et al. [49] compared PTW and SN emulsion-type sausages with $70 \mathrm{mg} / \mathrm{kg}$ nitrite using the Ames test, the results of which showed no differences between the samples. In additional toxicity tests where these sausages were fed to mice and where TNF- $\alpha$ levels, the intestinal length and the number of Peyer's patches were analyzed, neither indications of an inflammatory response nor differences between the feeding groups could be found. This indicates that PTW can be considered as a less risky and therefore suitable nitrite source for curing of meat products [49].

In a recent study, Yong et al. [47] investigated PTW and SN ham, cured with $70 \mathrm{mg} / \mathrm{kg} \mathrm{NO}_{2}{ }^{-}$, after 0,1 , and 2 weeks of frozen storage. The study showed that the PTW samples had higher a* values at all times and that, similar to the results of emulsion-type sausages, residual nitrite content was lower in PTW than in SN ham. No differences arose for the total aerobic bacteria count and lipid oxidation results. When using the Ames test, no genotoxic effect of the PTW could be obtained [47]. 
Jung et al. [50] who directly applied atmospheric pressure plasma (APP) on meat batters increased the nitrite content up to $66 \mathrm{mg} / \mathrm{kg}$ meat product. The authors showed a significant increase in the temperature $\left(0.2\right.$ up to $\left.20^{\circ} \mathrm{C}\right)$ and the $\mathrm{a}^{*}$ values and a significant decrease of the $\mathrm{pH}$ and $\mathrm{b}^{*}$ values during 30 min of plasma application. Although no antimicrobial effects or improvement of lipid oxidation were detected, the color results in another study indicated that direct plasma treatment of meat products might be an interesting curing alternative [52].

Similar to the results of the latter study, Lee et al. [51••] examined the suitability of APP for curing of canned ground ham. Although $1 \mathrm{~h}$ was necessary to generate about $60 \mathrm{mg} / \mathrm{kg}$ $\mathrm{NO}_{2}{ }^{-}$, APP treatment was stopped after $30 \mathrm{~min}$, as $42 \mathrm{mg} / \mathrm{kg}$ $\mathrm{NO}_{2}{ }^{-}$were produced and the intended temperature of $13^{\circ} \mathrm{C}$ has already been reached. The characteristics of APP ham were similar to the SN products. Additionally, no differences in the texture parameters were found, whereas better ratings for overall acceptability and taste in sensory testings were obtained for APP-cured ham [51••].

The suitability of APP to be used in the production of pork jerky in comparison to sodium nitrite was evaluated by Yong et al. [22••]. For this purpose, pork muscles were marinated in nitrite-free-brine and treated with APP for 0, 20, 40, and $60 \mathrm{~min}$, respectively. A similar nitrite content for $\mathrm{SN}$ and APP samples was achieved after $40 \mathrm{~min}$ of APP treatment. Again, the residual nitrite levels in APP samples were lower. Higher treatment duration increased the $\mathrm{L}^{*}$ and $\mathrm{a}^{*}$ and decreased the $\mathrm{b}^{*}$ results. If the pork jerky was inoculated with $S$. aureus and Bacillus cereus, APP treatment for 40 and 60 min decreased the microbial results compared to the $\mathrm{SN}$-treated groups. The findings of this study are of relevance, as it indicates that APP treatment can improve antimicrobial stability of treated products mainly due to the other constituents within the plasma [22••].

APP can cause a green discoloration of the treated meat. Yong et al. [52] related these changes to the structure of the porphyrin ring within the myoglobin and to the formation of green-colored nitrimyoglobin, as the use of reducing agents counteract the formation of this nitrimyoglobin.

Infusion of atmospheric non-thermal plasma (ANP) to ground ham resulted in similar color and lipid oxidation results compared to SN products [53*0]. The authors stated that an ANP infusion system can be readily implemented in the meat industry, as it is quite compatible to existing machines used in production. Furthermore, due to the longer inflow path of the plasma, possible effects on the temperature are reduced [53・0].

In 2019, Luo et al. [54•] published results of a study where dried pork loin was produced with PTW-curing brines. These brines were generated at three different voltages $(50,60,70$ $\mathrm{kV}$ ) within $1,2,3,4,5$, and 6 min of treatment. After 15 days of ripening, significantly decreasing $\mathrm{pH}$ values over time and decreasing nitrite contents up until 3-min treatment were obtained. The latter was explained by the higher transformation of $\mathrm{NO}_{2}{ }^{-}$to $\mathrm{NO}$ in low $\mathrm{pH}$ media. Besides this, $\mathrm{a}^{*}$ values rose with increasing voltage. Residual nitrite contents were higher and TBARS results lower in PTW-treated pork loins than SN products. The authors recommended $70-\mathrm{kV}$ treatment in the companies for production of curing meat products [54•]. In a further publication from this research group, Luo et al. [55] demonstrated a strong influence of cold plasma treatment on myofibrillar proteins in dry-cured bacon.

In 2020, Inguglia et al. [56 ] published a study on the production of beef jerky by using plasma, where they exposed solutions with $0,50,100$, and $150 \mathrm{ppm}$ sodium nitrite to air plasma or nitrogen $\left(\mathrm{N}_{2}\right)$ plasma treatment before adding these to the meat. Whereas after air plasma treatment $\mathrm{NO}_{2}{ }^{-}$concentrations increased, no effect was found after $\mathrm{N}_{2}$ plasma treatment. Processing the beef jerky with the air plasma-treated brines resulted in decreasing residual nitrite contents over time and higher $a^{*}$ values compared to products treated with $\mathrm{N}_{2}$ plasma brines or control brines without plasma treatment. Additionally, a reduction in inoculated L. innocua $\left(0.5 \log _{10}\right.$ $\mathrm{CFU} / \mathrm{g}$ ) could be found for plasma-treated samples after $18 \mathrm{~h}$ storage (only 0,50 , and $150 \mathrm{ppm}$ with and without air plasma treatment were taken into account) [56॰].

For further insights into the use of plasma technology in the meat industry, the review of Lee et al. [57] is suggested. This publication also recommends further investigations concerning food safety of plasma-treated products. As far as we know, nitrite and nitrate produced by plasma technology have not yet been approved for use in food products in the European Union with regard to existing food additive and probably also to novel food regulations.

\section{Production of Meat Products Without Addition of Nitrite or Nitrate}

The production of meat products without the addition of $\mathrm{NO}_{3}{ }^{-}$ and/or $\mathrm{NO}_{2}{ }^{-}$has been common for a long time in many countries (Fig. 2). These products are sometimes referred to as "white," and German examples are "Bavarian or Silesian white sausages" or "White Lyoner." Due to the possibly higher health risk of a production without nitrite, "white products" are preserved by other methods such as cooking or are only consumed after heating. Dry-cured ham is commonly produced by addition of $\mathrm{NO}_{2}^{-}$or $\mathrm{NO}_{3}{ }^{-}$. However, in countries such as Italy or Spain, raw ham is sometimes produced without the addition of nitrite or nitrate [58]. Preservation of these products is achieved by adding salt and drying of the ham for long periods. During this processing, the constituent zinc protoporphyrin $(\mathrm{ZnPP})$ is formed, which is responsible for the red color of these nitrite- or nitrate-free products in contrast to cured ham where nitrosomyoglobin mainly influences the color of the ham [59.•]. In $\mathrm{ZnPP}$, the heme iron of the myoglobin is replaced by zinc, which is influenced by the $\mathrm{pH}$ value and 
microorganisms. The precise mechanism of $\mathrm{ZnPP}$ formation is not clear until now $[59,60]$. However, independent of these differing color-related constituents in cured and uncured meat products, it has to be considered that removing the $\mathrm{NO}_{2}{ }^{-}$or $\mathrm{NO}_{3}{ }^{-}$might affect the microbiological safety of the uncured products, especially if contaminations during production or storage are not effectively reduced by other preservation methods. Products without nitrite or nitrate show higher growth of bacteria such as $\mathrm{Cl}$. perfringens, $\mathrm{Cl}$. botulinum, $\mathrm{S}$. aureus, L. monocytogenes, Salmonella enterica, or E. coli [12, 24, 33, 61-65]. Besides these clear effects of nitrite on the microbial parameters of the products, other quality parameters should also be considered. For example, in raw pork ham or cooked pork sausages without nitrite or nitrate, the instrumental redness ( $\left.a^{*}\right)$ values and the color and overall acceptability results after sensory analysis are lower, whereas the TBARS concentrations, an indicator of lipid oxidation processes, are higher compared to meat products with added nitrite [37, 63, 66-68]. Although the differing color and sensory parameters can negatively influence the consumer acceptance of the nitrite- or nitrate-free products, these parameters are less relevant for food safety. In contrast, increased TBARS results might be problematic for consumer health, as lipid oxidation can induce oxidative stress which is involved in many diseases and as a last consequence may lead to the development of cancer $[69,70]$.

\section{Conclusions}

Under consideration of certain specific characteristics, especially color and flavor, curing with plants or plant extracts or with plasma as well as plasma-treated water are reasonable curing alternatives used in meat product manufacturing. However, curing by using these alternative methods is still problematic, as official approval of each plant (extract) as food additives or plasma-generated nitrite and nitrate, for example, as novel food might be necessary in certain countries. The addition of plant (extracts) and plasma treatment can result in sufficient amounts of nitrate and nitrite in the meat products, whereas addition of plasma-treated water is limited to the manufacturing of certain meat products such as cooked sausages. In general, the obtained meat products are similar to conventionally cured products if similar $\mathrm{NO}_{2}^{-}$or $\mathrm{NO}_{3}{ }^{-}$concentrations are applied. These comparable results make the changeover to alternative nitrite sources for use in meat products less worthwhile, especially as the nitrite or nitrate from these sources are chemically identical to curing salt. However, some studies justify the use of these alternatives by showing reduced residual nitrite contents of plant (extracts)-cured meat products as well as plasma-cured ones. This clear benefit regarding human health due to possible reduced nitrosamine formation stands in contrast to the disadvantage of reduced microbial safety, for example, after recontamination of the products.
Funding Open Access funding enabled and organized by Projekt DEAL.

\section{Declarations}

Human and Animal Rights and Informed Consent This article does not contain any studies with human or animal subjects performed by any of the authors.

Conflict of Interest Lisa Siekmann, Carsten Krischek, and Madeleine Plötz declare that they have no conflicts of interest.

Open Access This article is licensed under a Creative Commons Attribution 4.0 International License, which permits use, sharing, adaptation, distribution and reproduction in any medium or format, as long as you give appropriate credit to the original author(s) and the source, provide a link to the Creative Commons licence, and indicate if changes were made. The images or other third party material in this article are included in the article's Creative Commons licence, unless indicated otherwise in a credit line to the material. If material is not included in the article's Creative Commons licence and your intended use is not permitted by statutory regulation or exceeds the permitted use, you will need to obtain permission directly from the copyright holder. To view a copy of this licence, visit http://creativecommons.org/licenses/by/4.0/.

\section{References}

Papers of particular interest, published recently, have been highlighted as:

- Of importance

•• Of major importance

1. Binkerd EF, Kolari OE. The history and use of nitrate and nitrite in the curing of meat. Food Cosmet Toxicol. 1975;13:655-61.

2. Cassens RG, Ito T, Lee M, Buege D. The use of nitrite in meat. BioScience. 1978;28(10):633-7.

3. Sindelar JJ. Natural and organic cured meat products in the United States. In: Dikeman M, Devine C, editors. Encyclopedia of Meat Sciences. Oxford: Elsevier Ltd.; 2014. p. 430-5.

4. European Commission. Regulation (EC) No $1333 / 2008$ of the European Parliament and of the Council of 16 December 2008 on food additives. Amended by Commission Regulation (EU) $\mathrm{Nr}$ 1129/2011 of 2011 Amending Annex II to Regulation (EC) No $1333 / 2008$ of the European Parliament and of the Council by establishing a Union list of food additives.

5. Sebranek JG, Bacus JN. Cured meat products without direct addition of nitrate or nitrite: what are the issues? Meat Sci. 2007;77: 136-47.

6. Honikel KO. The use and control of nitrate and nitrite for the processing of meat products. Meat Sci. 2008;78:68-76.

7. Parthasarathy DK, Bryan NS. Sodium nitrite: The "cure" for nitric oxide insufficiency. Meat Sci. 2012;92:274-9.

8. Karwowska M, Kononiuk A. Nitrates/nNitrites in food- risk for nitrosative stress and benefits. Antioxidants. 2020;9:241.

9. Roberts TA, Ingram M. Inhibition of growth of $\mathrm{Cl}$. Botulinum at different $\mathrm{pH}$ values by sodium chloride and sodium nitrite. J Food Technol. 1973;8:467-75.

10. Tompkin RB. The role and mechanism of the inhibition of C. botulinum by nitrite is a replacement available? In Proceedings: 31 st Annual Reciprocal Meat Conference of the American Meat Science 
Association, Storrs, Conn. Chicago: National Livestock and Meat Board. p. 135-47.

11. Sauter EA, Kemp JD, Langlois BE. Effect of nitrite and erythorbate on recovery of Clostridium perfringens spores in cured pork. J Food Sci. 1977;42(6):1678-9.

12. Jackson AL, Sullivan GA, Kulchaiyawat C, Sebranek JG, Dickson JS. Survival and growth of Clostridium perfringens in commercial no-nitrate-or-nitrite-added (natural and organic) Frankfurters, hams and bacon. J Food Prot. 2011;74(3):410-6.

13. King AM, Glass KG, Milkowski AL, Sindelar JJ. Impact of cleanlabel antimiocrobials and nitrite derived from natural sources on the outgrowth of Clostrisium perfringens during cooling of deli-style turkey breast. J Food Prot. 2015;87(5):946-53.

14. Sindelar JJ, Milkowski AL. Human safety controversies surrounding nitrate and nitrite in the diet. Nitic Oxide. 2012;26:259-66.

15. Pegg RB, Shahidi F. Flavor development. In: Dikeman M, Devine C, editors. Encyclopedia of Meat Sciences, vol. 1. Oxford: Elsevier Ltd; 2014. p. 377-84.

16. Gassara F, Kouassi AP, Brar SK, Belkacemi K. Green Alternatives to nitrates and nitrites in meat-based products- a review. Crit Rev Food Sci Nutr. 2016;56:2133-48.

17. EFSA ANS Panel (EFSA Panel on Food Additives and Nutrient Sources added to Food), Mortensen A, Aguilar F, Crebelli R, Di Domenico A, Dusemund B, et al. Scientific oOpinion on the reevaluation of sodium nitrate (E 251) and potassium nitrate (E 252) as food additives. EFSA J. 2017;15(6):4787. https://doi.org/10. 2903/j.efsa.2017.4787.

18. EFSA ANS Panel (EFSA Panel on Food Additives and Nutrient Sources added to Food), Mortensen A, Aguilar F, Crebelli R, Di Domenico A, Dusemund B, et al. EFSA J. 2017;15(6):4786. https:// doi.org/10.2903/j.efsa.2017.4786.

19. Kalaycioglu Z, Erim FB. Nitrate and nitrites in foods: wWorldwide regional distribution in view of their risks and benefits. J Agric Food Chem. 2019;67:7205-22.

20. Barbieri G, Bergamaschi M, Franceschini M. Kinetics of nitrite evaluated in a meat product. Meat Sci. 2013;93:282-6.

21. Jung S, Kim HJ, Park S, Yong HI, Choe JH, Jeon HJ, et al. The use of atmospheric pressure plasma-treated water as a source of nitrite for emulsion-type sausage. Meat Sci. 2015;108:132-7.

22.• Yong HI, Lee SH, Kim SY, Park S, Park J, Choe W, et al. Color development, physicochemical properties, and microbiological safety of pork jerky processed with atmospheric pressure plasma. Innov Food Sci Emerg Technol. 2019;53:78-84 In this study, the processing of pork jerky using different times of atmospheric pressure plasma treatment is investigated. Physicochemical as well as microbiological properties are analysed.

23. Jo K, Lee S, Yong HI, Choi YS, Jung S. Nitrite sources for cured meat products. LWT. 2020;129:109583.

24.• Riel G, Boulaaba A, Popp J, Klein G. Effects of parsley extract powder as an alternative for the direct addition of sodium nitrite in the production of mortadella-type sausages- ilmpact on microbiological, physicochemical and sensory aspects. Meat Sci. 2017;131: 166-75 As one of the few studies, this publication deals with the use of parsley as a nitrite source. It also shows promising results for the production of mortadella type sausages with different extract concentrations.

25. Hwang K-E, Kim T-K, Kim H-W, Oh N-S, Kim Y-B, Jeon K-H, et al. Effect of fermented red beet extracts on the shelf stability of low salt frankfurters. Food Sci Biotechnol. 2017;26(4):929-36 This study demonstrates the potential of curing with different concentrations of beetroot. Physicochemical, microbiological values as well as results of sensory evaluation are presented.

26. Choi JH, Bae SM, Jeong JY. Effects of the addition levels of white kimchi powder and acerola juice powder on the qualities of indirectly cured meat products. Food Sci Anim Resour. 2020;40(4): 636-48.
27. Jeong JY, Bae SM, Yoon J, Jeong DH, Gwak SH. Effect of using vegetable powders as nitrite/nitrate sources on the physicochemical characteristics of cooked pork products. Food Sci Anim Resour. 2020;40(5):831-43 This study shows differences in the product properties and the potential of curing with radish powder, spinach powder or Chinese cabbage powder.

28. Rava M, Varraso R, Decoster B, Huyvaert H, Le Moural N, Jacquemin B, et al. Plasma and exhaled breath condensate nitritenitrate level in relation to environmental exposures in adults in the EGEA study. Nitric Oxide. 2012;27:169-75.

29. Vitturi DA, Patel RP. Current perspectives and challenges in understanding the role of nitrite as an integral player in nitric oxide biology and therapy. Free Radic Biol Med. 2011;51:805-12.

30. Habermeyer M, Roth A, Guth S, Diel P, Engel KG, Epe B, et al. Nitrate and nitrite in the diet: hHow to assess their benefit and risk for human health. Mol Nutr Food Res. 2015;59:106-28.

31. Alahakoon AU, Jayasena DD, Ramachanda S, Jo C. Alternatives to nitrite in processed meat: uUp to date. Trends Food Sci Technol. 2015;45:37-49.

32. Bedale W, Sindelar JJ, Milkowski AL. Dietary nitrate and nitrite: Benefits, risks, and evolving perceptions. Meat Sci. 2016;120:8592.

33. King AM, Glass KA, Milkowski AL, Sindelar JJ. Comparison of the effect of curing ingredients derived from purified and natural sources in inhibition of Clostridium perfringens outgrowth during cooling of deli-style turkey breast. J Food Prot. 2015;78(8):152735 .

34.• Ko YM, Park JH, Yoon KS. Nitrite formation from vegetable sources and its use as a preservative in cooked sausage. J Sci Food Agric. 2017;97:1774-83 The authors present a comprehensive study of several relevant plant-based nitrite sources such as spinach, lettuce, white as well as young radish and commercial cabbage powder.

35. Pietrasik Z, Gaudette NJ, Johnston SP. The use of high pressure processing to enhance the quality and shelf life of reduced sodium naturally cured restructured cooked hams. Meat Sci. 2016;116: 102-9.

36. Kawski VL, Bertol TM, dos Santos MJH, Sawitzki MC, Fiorentini AM, Coldebella A, et al. Sensory and physicochemical characteristics of salamis added with vegetable-based curing ingredients. Cienc Rural. 2017;47(8):783-92 These authors show that vegetable-based curing ingredients can achieve comparable effects to commercial products if an appropriate ripening period is assured.

37. Hwang K-E, Kim T-K, Kim H-W, Seo D-H, Kim Y-B, Jeon K-H, et al. Effect of natural pre-converted nitrite sources on color development in raw and cooked pork sausage. Asian-Australas J Anim Sci. 2018;31(8):1358-65.

38. Kim T-K, Yong HI, Jang EW, Lee H, Kim Y-B, Jeon K-H, et al. Quality of sliced cured pork loin with spinach: effect of incubation period with starter culture. J Food Qual. 2019;2019:6373671 The article provides interesting insights into the conversion of nitrate to nitrite from spinach extracts over time.

39. Rivera N, Bunning M, Martin J. Uncured-labeled meat products produced using plant-derived nitrates and nitrites: cChemistry, safety, and regulatory considerations. J Agric Food Chem. 2019;67: 8074-84.

40. Krause BL, Sebranek JG, Rust RE, Mendonca A. Incubation of curing brines for the production of ready-to-eat, uncured, no-nitrite-or-nitrate-addeds, ground, cooked and sliced ham. Meat Sci. 2011:89:507-13.

41. Li P, Kong B, Chen Q, Zheng D, Liu N. Formation and identification of nitrosylmyoglobin by Staphylococcus xylosus in raw meat batters: aA potential solution for nitrite substitution in meat products. Meat Sci. 2013;93:61-72. 
42. Szymański P, Laszkiewicz B, Siekierko U, Kolożyn-Krajewska. Effects of the use of Staphylococcus carnosus in the curing process of meat with a reduced amount of sodium nitrite on colour, residue nitrite and nitrate, content of nitrosyl pigments, and microbiological and the sensory quality of cooked meat product. J Food Qual. 2020;2020:6141728.

43. Oehmigen K, Hähnel M, Brandenburg R, Wilke C, Weltmann KD, von Woedtke T. The role of acidification for antimicrobial activity of atmospheric pressure plasma in liquids. Plasma Process Polym. 2010;7:250-7.

44. Thirumdas R, Sarangapani C, Annapure US. Cold plasma: aA novel non-thermal technology for food processing. Food Biophys. 2015;10:1-11.

45. Bruggemann PJ, Kushner MJ, Locke BR, Gardeniers JGE, Graham WG, Graves DB, et al. Plasma-liquid interactions: a review and roadmap. Plasma Sources Sci Technol. 2016;25:053002.

46. Vlad IE, Anghel SD. Time stability of water activated by different on-liquid atmospheric pressure plasmas. J Electrost. 2017;87:28492.

47. Yong HI, Park J, Kim JJ, Jung S, Park S, Lee HJ, et al. An innovative curing process with plasma-treated water for production of loin ham and for its quality and safety. Plasma Process Polym. 2017;15:e1700050.

48. Jung S, Kim HJ, Park S, Yong HI, Choe JH, Jeon JH, et al. Color developing capacity of plasma treated water as a source of nitrite for meat curing. Korean J Food Sci An. 2015;35(5):703-6.

49. Kim HJ, Sung NY, Yong HI, Kim H, Lim Y, Ko KH, et al. Mutagenicity and immune toxicity of emulsion-type sausage cured with plasma-treated water. Korean J Food Sci Anim Resour. 2016;36(4):494-8.

50. Jung S, Lee J, Lim Y, Choe W, Yong HI, Jo C. Direct infusion of nitrite into meat batter by atmospheric pressure plasma treatment. Innov Food Sci Emerg Technol. 2017;39:113-8.

51.• Lee J, Jo K, Lim Y, Jeon HJ, Choe JH, Jo C, et al. The use of atmospheric pressure plasma as a curing process for canned ground ham. Food Chem. 2018;240:430-6 This study provides a thorough description of treating meat batter directly with atmospheric pressure plasma to increase nitrite content for curing of canned ground ham.

52. Yong HI, Han M, Kim HJ, Suh JY, Jo C. Mechanism underlying green discolouration of myoglobin induced by atmospheric pressure plasma. Sci Rep. 2018;8:9790.

53.• Jo K, Lee J, Lee S, Lim Y, Cho YS, Jo C, et al. Curing of ground ham by remote infusion of atmospheric non-thermal plasma. Food Chem. 2020;309:125643 In this study, a new remote infusionsystem was investigated for curing ground ham with atmospheric non-thermal plasma.

54. Luo J, Yan W, Nasiru MM, Zhuang H, Zhou G, Zhang J. Evaluation of physicochemical properties and volatile compounds of Chinese dried pork loin curing with plasma-treated water brine. Sci Rep. 2019;9:13793 This study provides a thorough description of curing pork loin with plasma-treated water brine. Factors such as treatment duration, voltage intensity, $\mathrm{pH}$ and nitrite content are compared and volatile compounds are analysed.

55. Luo J, Nasiru MM, Yan W, Zhuang H, Zhou G, Zhang J. Effects of dielectric barrier discharge cold plasma treatment on the structure and binding capacity of aroma compounds of myofibrillar proteins from dry-cured bacon. LWT. 2020;117:108606.

56. Inguglia ES, Oliveira M, Burgess CM, Kerry JP, Tiwari BK. Plasma-activated water as an alternative nitrite source for the curing of beef jerky: Influence on quality and inactivation of Listeria innocua. Innov Food Sci Emerg Technol. 2020;59:102276 This study gives a good insight into the experimental design and the influence of plasma-activated water on the growth of Listeria innocua when used for curing beef jerky.

57. Lee J, Lee CW, Yong HI, Lee HJ, Jo C, Jung S. Use of atmospheric pressure cold plasma for meat industry. Korean J Food Sci Anim Resour. 2017;37(4):477-85.

58. Parolari G, Aguzzoni A, Toscani T. Effects of processing temperature on color properties of dry-cured hams made without nitrite. Foods. 2016;5:33. https://doi.org/10.3390/foods5020033.

59.• Wakamatsu J, Kawazoe H, Ohya M, Hayakawa T, Kumura H. Improving the color of meat products without adding nitrite/ nitrate using high zinc protoporphyrin IX-forming microorganisms. Meat Sci. 2020;161:107989 This publication presents some data about an important mechanism related to the color of ham without addition of nitrite/nitrate.

60. Delcanale P, Montali C, Rodriguez-Amigo B, Abbruzzetti S, Bruno $\mathrm{S}$, Bianchini $\mathrm{P}$, et al. Zinc-substituted myoglobin is a naturally occurring photo-antimicrobial agent with potential applications in food decontamination. J Agric Food Chem. 2016;64:8633-9.

61. Lamas A, Miranda JM, Vazquez B, Cepeda A, Franco CM. An evaluation of alternatives to nitrites and sulfites to inhibit the growth of Salmonella enterica and Listeria monocytogenes in meat products. Foods. 2016;5:74

62. Mainar MS, Xhaferi R, Samapundo S, Devlieghere F, Leroy F. Opportunities and limitnations for the production of safe fermenteds meats without nitrate and nitrite using an antibacterial Staphylococcus sciuri starter culture. Food Control. 2016;69:267-74.

63. Stadnik J, Stasiak DM. Effect of acid whey on physicochemical characteristics of dry-cured organic pork loins without nitrite. Int J Food Sci Technol. 2016;51:970-7.

64. Hospital XF, Hierro E, Arnau J, Carballo J, Aguirre JS, GratacosCubarsi M, et al. Effect of nitrate and nitrite on Listeria and selected spoilage bacteria inoculated in dry-cured ham. Food Res Int. 2017;101:82-7.

65. Lee S, Lee H, Kim S, Lee J, Ha J, Choi Y, et al. Microbiological safety of processed meat products formulated with low nitrite concentration - a review. Asian Austr J Anim Sci. 2018b;31:1073-7.

66. Seong PN, Ba HV, Kim SS, Kang SM, Cho SH, Kim JH, et al. Effects of additions of Monascus and Laccaic acid on the color and quality properties of nitrite-free emulsion sausage during refrigerated storage. Korean J Food Sci Anim Resour. 2017;37:10-7.

67. Kim TK, Lee MA, Sung JM, Jeon KH, Kim YB, Choi YS. Combination effects of nitrite from fermented spinach and sodium nitrite on quality characteristics of cured pork loin. Asian Austr J Anim Sci. 2019a;32:1603-10.

68. Kim TK, Hwang KE, Song DH, Ham YK, Kim YB, Paik HD, et al. Effects of natural nitrite source from Swiss chard on quality characteristics of cured pork loin. Asian Austr J Anim Sci. 2019b;32: 1933-41.

69. Huang X, Ahn DU. Lipid oxidation and its implications to meat quality and human health. Food Sci Biotechnol. 2019;28:1275-85 This publication presents important data about the effect of oxidation.

70. Jackson V, Penumetcha M. Dietary oxidised lipids, health consequences and novel food technologies that thwart food lipid oxidation: an update. Int J Food Sci Technol. 2019;54:1981-8 This publication presents important data about the effect of oxidation.

Publisher's Note Springer Nature remains neutral with regard to jurisdictional claims in published maps and institutional affiliations. 